moved on, the newcomers think it sounds quite easy, and no one can remember just how difficult it was last time. Fortunately, the audience has either forgotten the previous fiasco or is looking forward to another.

Zodwa the kitchen woman has arrived with her drum kit. A couple of student nurses spent an hour yesterday putting us through our paces. We have all furtively changed into theatre greens and wellies in the physiotherapy room and are polishing up our boot slapping technique for one last time. And then another prayer ends and it is time for us to go on.

Our opening lines are brief, and with a drum roll from Zodwa we are in action. Three steps forward, three steps back, turns to the right or left, and a whole lot of boot slapping. Even before the end of the first manoeuvre we are all out of step, but the audience seems all the more pleased. Soon the drum beats are almost drowned by the hoots from the audience, and by now we are all doing something completely different. An unreliable piece of elastic in my theatre gown threatens to add an extra nuance to our performance, and I think one of my colleagues has lost her left boot in the audience. Eventually, despite Zodwa's enthusiasm to continue drumming all afternoon, we manage to achieve a dramatic exit from the dining room, green gowns and flailing limbs still flapping long after the music has stopped.
With our performance over, we can relax and enjoy the rest of the programme. We are followed, rather tactlessly, by some real Zulu dancing, which is very impressive, but lacks our spontaneity, perhaps. Some sketches follow which even survive furtively whispered translation. Undoubtedly the highlight of the afternoon is a nativity sketch by the domestic staff, featuring our largest cleaning lady as King Herod. Unfortunately, the theatre nurses' item, which we had all been looking forward to, is thwarted by an untimely caesarean section.

Eventually the last items are finished, the final hymn sung, and the closing prayer completed. The crowd emerges from the dining room into the warmth of the summer afternoon sunshine and loiters while Christmas greetings are exchanged. The hospital is already starting to feel quiet, as many of the staff who are not working over Christmas have packed to go and see their families elsewhere. I walk back over towards the main hospital building, and return my boots to the theatre changing room. The wards are almost empty, and the nurses have had time to fix up some Christmas decorations. Outpatients is deserted, the last bus having left a few hours ago. And the labour ward looks calm; there is no one pacing the corridor or leaning awkwardly against the wall. So maybe we are on course for a quiet Christmas this year.

\title{
Information sharing: getting journals and books to developing countries
}

\section{Trish Groves}

\begin{abstract}
This year we subscribed to 150 journals, which is 11 fewer than the previous year. The total cost is over $£ 21000$, double the amount spent for the same number of journals in $1990 \ldots$ A good library with an adequate periodical base enriches students and teachers. Without this facility the search for new knowledge is impossible. ${ }^{1}$
\end{abstract}

In the late 1980s the university library [in Sri Lanka] received nearly 1370 periodicals on subscription or exchange or as gifts. By 1990 this was reduced to 275 subscriptions. In 1991 not a single subscription was renewed, due to lack of funds.

Doctors in the world's poorest countries, like the two quoted above, are missing out on up to date information about medicine, science, and technology because neither they nor their libraries can afford to buy journals and books. In many cases this is because donors from richer countries are no longer willing or able to send money and free publications. But there are still many institutions, publishers, and individuals who want to help. Their main problem is that they do not know where or how to send the information in a useful and affordable way. And, although numerous donation and distribution schemes are already up and running - some of which are outlined in this articlethey have not been particularly well publicised or coordinated in the past.

Things are set to improve. In the spring of 1992 a new cooperative organisation called the International Network for the Availability of Scientific Publications (INASP) was set up. It aims to support and strengthen existing programmes involved in the publication, distribution, exchange, and donation of books, journals, and related materials and to encourage new initiatives that will increase the availability of quality scientific literature. Established by the International Council of Scientific Unions and supported by the European Commission and Unesco, the network has already compiled an extensive computerised database. The first part of this details institutions that have indicated a wish for academic assistance, and the second part includes information on organisations that can provide support. The network offers a clearing house and advisory service and assists in matching donors, be they individuals, libraries, or organisations, to appropriate recipients and vice versa. This year the first annual directory of network members was published, giving names and addresses and comprehensive summaries of the services on offer. Early next year a copy of the complete database will be available on diskette. ${ }^{2}$

The director of INASP, Carol Priestley, is anxious to point out that literature donation from Northern and Western countries is at best only an emergency stopgap. At worst, donation schemes represent cultural imperialism and stifle the initiative of local publishers. In the long run rich countries can help poorer ones best by encouraging and sustaining good indigenous research, publishing, and information sharing. After all, for the foreseeable future, scientifically reliable studies on, say, river blindness and tuberculosis will probably be more valuable to African researchers than studies on screening in British general practice and cardiac catheterisation. On the other hand, most readers and researchers in the more privileged world still have a lot to learn about health in developing countries. Indigenous data sharing needs extensive support, however, covering everything from teaching editing skills to encouraging local production of printable paper and providing toner for computer printers. Working towards providing information on this more distant goal, INASP is developing a database of journals published in sub-Saharan Africa and is setting up a pilot project to distribute the journals round the continent.

For individual doctors who just want to know a bit
Trish Groves, assistant editor

BMF 1993;307:1015-7 
more about this kind of overseas aid or want to donate their old (but not too old) journals, here is a quick and by no means comprehensive round up of the most accessible schemes (see box for summary and appendix for addresses). The schemes fall into two main categories: those providing information at no cost and those providing it at affordable prices.

\section{Free information}

FROM INDIVIDUALS

Starting at the most personal and local level, there are several ways in which doctors and scientists can send or redirect their own journals to needy contacts abroad. Many doctors want to be able to pass their journals on, not least because they consider that receiving two or more identical journals in their medical households, general practices, or clinical firms is downright wasteful. Many are tied to paying the subscription fees as conditions of membership of their professional bodies, whether or not they want to read the journals. The stumbling blocks for most of these willing donors are logistic: they do not know who needs what overseas and they cannot realistically afford the postage.

In Britain, willing journal donors can use the International Campus Book Link (ICBL). This service matches up supply and demand for journals in Africa and pays for their distribution. Sponsored by Barclays Bank, the Overseas Development Administration, and the British Council, ICBL ensures that donated books and journals go to the African universities and academic institutions that have requested those specific titles. The scheme is understandably choosy; it accepts only recent publications in good condition (up to five years old for medicine, up to 10 for certain pure and engineering sciences) and firmly promised runs of consecutive journals. The ideal donation from an individual doctor is a "delayed subscription"-a bundle comprising the entire volume of a single journal from the previous year. Since February, when ICBL's project manager Ard Jongsma explained the scheme in the Lancet $^{3}$ he has been inundated with offers of journals from doctors.

The ICBL scheme is a specific project managed by another organisation based in Britain, Book Aid International (formerly the Ranfurly Library Service) and it uses the service's distribution network to get the journals to their destinations. (This does not mean, however, that doctors should take their journals directly to Book Aid International-this service is primarily geared to book donation and can handle

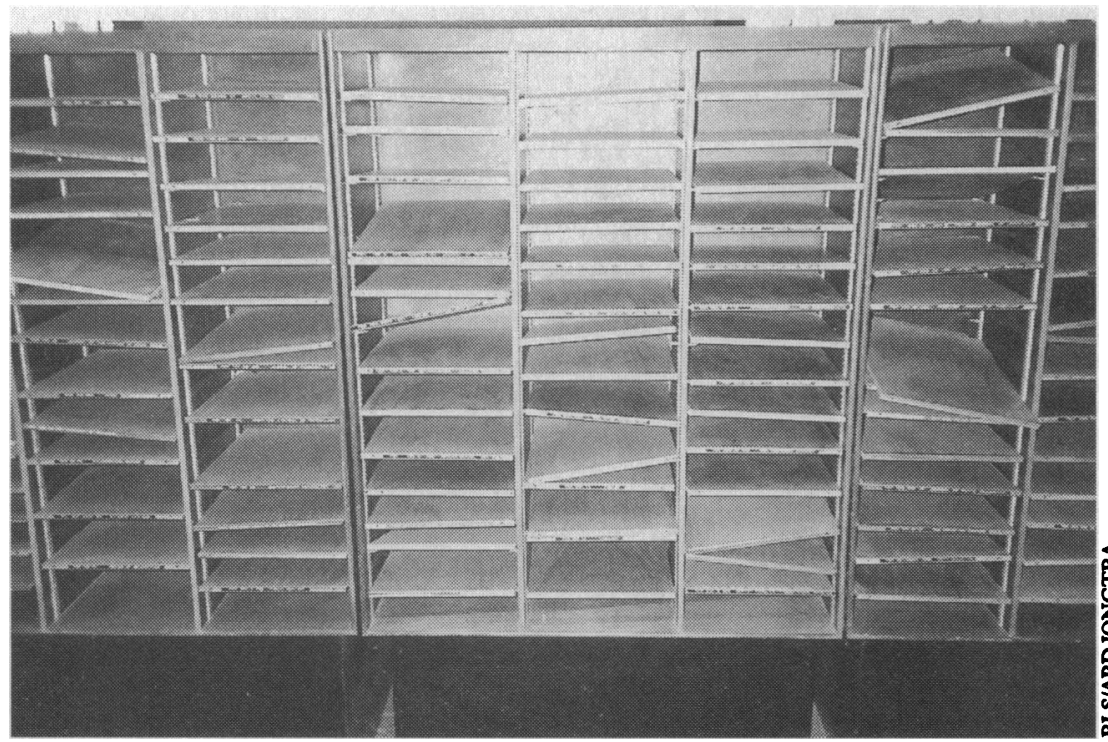

In Addis Ababa-as elsewhere-library shelves are empty for want of funds for subscriptions to journals, a gap that individuals and institutions can help to fill
Some schemes that get health information through to developing countries

Free information

From individuals:

International Campus Book Link

Book Aid International

Gift subscriptions to journals (for example, Nature)

From academic bodies:

Urolink

World Anaesthesia

Pharmaid (old $B N F$ s)

American Association for the Advancement of Science

From publishers:

$N E \mathcal{F M}, B M \mathcal{J}$

WHO, EC, Commonwealth Secretariat

Affordable information

Low priced journals:

$B M \mathcal{F}$ and Nature monthly editions

Low priced books:

Educational Low-Priced Books Scheme

Electronic data:

Bibliographic services

SatelLife

Coordinating bodies

International Network for the Availability of Scientific Publications (INASP)

journals only in reasonable bulk through ICBL.)

Book Aid International is an aid charity that sends secondhand and surplus books to some 70 needy countries every year, including those in eastern Europe. It is funded by benefactors as diverse as the British government's Overseas Development Administration and the Sultan of Brunei. The service sorts, packs, and dispatches the books at its warehouse in Camberwell, London, and delivers them by various routes to selected institutions, communities, and projects. In 1991 nearly 1.3 million books were given to the service: Rotary clubs were the biggest single source. Of the total that year some 700000 were sufficiently relevant and well preserved to send; most were for general school and university education, but nearly 36000 were medical books.

Outside Britain there are four main organisations which, among other educational activities, target and distribute literature to developing countries, particularly in Africa. They are the Swedish Agency for Research Cooperation with Developing Countries (SAREC), the Netherlands Universities Foundation for International Cooperation in Higher Education (NUFFIC), the Australian Centre for Publication Acquired for Development (ACPAD), and the international division of the American Association for the Advancement of Science (AAAS). Around 20 countries in eastern Europe and the former Soviet Union are supplied through a scheme based in New York, the East and Central Europe Journal Donation Project. Details and addresses of all of these organisations are given in the INASP directory.

Individual subscribers can send their journals to poorer countries directly through the publishers, but very few medical and scientific publishers run such schemes. In Britain the science journal Nature will send gift subscriptions to nominated recipients in eastern Europe. The British subscriber simply pays $£ 85$ and gives the recipient's name and address and Nature does the rest-to date more than 100 gift 


\section{Satellife}

SatelLife is an international not-for-profit organisation based in Massachusetts that beams up to date information on health to developing countries by satellite. It has provided ground stations (each is relatively low tech, comprising a radio and antenna and a computer terminal) in Cameroon, Congo, Ghana, Kenya, Mozambique, Tanzania, Uganda, Zambia, Zimbabwe, Brazil, and Cuba. As well as providing on line literature searches Satellife allows clinicians and researchers at the various ground stations to communicate quickly with each other-a vital service in countries where post and telecommunications are poor. Finally, the system provides regular access to several electronic publications, including an international AIDS bulletin and the New England fournal of Medicine's "Journal Watch" newsletter.

subscriptions have been arranged. In the United States the journal Ophthalmology is setting up a similar system of gift subscriptions in a move to what it calls informational recycling.

\section{FROM ACADEMIC ORGANISATIONS}

Many medical specialist bodies develop partnership links between their members and colleagues overseas which facilitate the exchange and donation of up to date literature on a small scale. Examples include the British Association of Urological Surgeons' Urolink network and the World Anaesthesia scheme based in Exeter, England.

The Royal Pharmaceutical Society of Great Britain and the British Medical Association, joint publishers of the British National Formulary, send recent and unwanted copies of this essential prescribing guide to developing countries in the British Commonwealth every year. This year doctors were asked to hand in their formularies to pharmacists during the first week of November, along with unwanted copies of the 29th edition of the Martindale pharmacopoeia.

\section{FROM PUBLISHERS}

Many medical publishers send journals to institutions and individual doctors in poorer countries. For instance the New England fournal of Medicine has been sending around 500 free subscriptions to eastern Europe for the past four or five years. The journal hired a consultant to visit academics in Poland, Hungary, Romania, the former Czechoslovakia, and the former Soviet Union and draw up a list of suitable recipients. This scheme partly satisfies the NEFM's overall mission to inform and educate, and it also makes sound commercial sense-at least some of the current recipients of free journals will be willing to pay for their subscriptions when their countries' economies improve.

For developing countries the NEfM's policy reflects that of many medical publishers: it sends free copies in response to requests and considers each individually, rather than following any clear strategy. The $B M \ngtr$ has a similar request led approach, sending free copies or swapping them with journals from other publishers and academic bodies who ask and seem suitable.

In addition, international bodies like the World Health Organisation, the European Commission, and the Commonwealth Secretariat-which produce regular publications that do not routinely get into libraries and bibliographic databases-send free copies of their own publications to selected educational institutions in developing countries.

\section{Sending afiordable information} JOURNALS

The $B M$ f has recently lowered the subscription rate to its weekly international edition by nearly half to $£, 90$ ( $\$ 137$ for American subscribers). For many readers overseas this is still too expensive, but those in several countries including India, Pakistan, Poland, and Mexico can subscribe to monthly oveseas editions of the $B M \mathcal{f}$ at an average of $£ 12(\$ 18)$ a year.

These monthly editions are translated and published under licence in the countries and contain papers, editorials, and other articles chosen from the weekly $B M$ F, along with locally produced editorial copy. They allow affordable access to the $B M \mathcal{F}$ in readers' own languages, reflect local issues and needs, and, hopefully, stimulate indigenous research and publishing. There are also spin offs for the BMJ Publishing Group: these editions take the $B M F$ to places where the full weekly journal is not yet commercially viable, forge closer links between the group's editorial and production staff and their colleagues overseas, and may increase the submission to the $B M F$ of papers from the countries concerned.

Nature has a similar monthly edition specially for countries in the Commonwealth of Independent States (the former Soviet Union), which costs subscribers there just 600 roubles-around 30 pence sterlingeach year. Within a year of its launch, Monthly Nature has established a circulation of around 2500 scientists. It will soon be available in Hungary, Poland, the Czech Republic, and Slovakia.

\section{Books}

The British government's Overseas Development Administration subsidises publishers to provide a special selection of undergraduate and postgraduate textbooks through the Educational Low-Priced Books Scheme (ELBS). The books cover business studies, education, engineering and technology, law, medicine, nursing, and science and cost between a third and a fifth of the cheapest standard paperback editions available in Britain.

Despite being cheap, the low price editions are complete and unabridged and are of the same material quality as the British editions. They are up to dateonly new publications or those with new editions in the past five years are included in the scheme. And they are relevant, being chosen by academic advisers around the world. The books are distributed to 54 developing countries and are available from appointed local stocklists and British exporting wholesalers and retailers.

\section{ELECTRONIC DATA}

In 1991 Carol Priestley was commissioned by the Commonwealth Secretariat to explore the possibility of setting up a coordinated programme of information sharing within the Commonwealth. As part of her remit she surveyed 112 universities, libraries, and academic bodies in the Commonwealth and asked them what kind of information they most needed. At the time, nearly all put current journals at the top of their lists. Since then, increasing numbers of academics in the developing world have requested electronic data, particularly in the relatively cheap and robust CD-ROM form.

Many national and international libraries provide on line literature searches and document supply (abstracts and articles sent by post, modem, and electronic mail), both to and within the developing world. One scheme has gone a stage further-up into space. The Satellife service, based in Cambridge, Massachusetts, has licensed and installed simple and relatively low cost ground stations in 11 developing countries to provide electronic information on health (box).

\section{The future of information sharing}

It is impossible to do justice in one article to the

.


diversity and extent of the many schemes that make information on health more widely available to people in developing countries. We hope that organisations and individuals who know about the subject will write and tell use more.

In the near future the $B M \mathcal{F}$ hopes to make itself more accessible to doctors and researchers overseas who cannot afford the normal subscriptions. As a first step the $B M F$ is organising a conference to bring together publishers, donors, and recipients of information on medicine and science to increase understanding and cooperation. Details of the conference are not yet finalised, but anyone who is interested in participating or attending should contact the editor, Richard Smith.

1 Skandhan KP. Journals for developing countries. Lancet 1992;340:1165. 2 International Network for the Availability of Scientific Publications. INASP directory 1993. London: ICSU Press, 1993.

3 Jongsma A. Journals for developing countries. Lancet 1993;341:376.

\section{Useful addresses}

Nature Marketing (for gift subscriptions)

4 Little Essex Street

London WC2R 3LF
International Network for the Availability of Scientific Publications (INASP)

PO Box 2564

London W5 1ZD

telephone 0819973274

fax 0918109795

International Campus Book Link (ICBL)

Book Aid International

39/41 Coldharbour Lane

London SE5 9NR

telephone 0717333577

fax 0719788006

Pharmaid, Commonwealth Pharmaceutical Association

1 Lambeth High Street

London SE1 7JN

telephone 0717359141

Educational Low-Priced Books Scheme (ELBS)

International Book Development Ltd

6 Devonhurst Place

Heathfield Terrace

London W4 4JD

\section{Cover story: Kitaj's "Heart Attack"}

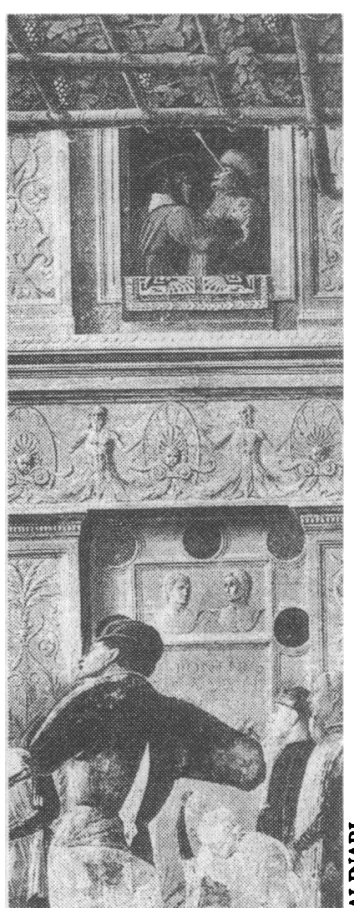

$A$ detail of Mantegna's "The Martyrdom of St Christopher"
After my heart attack I got very interested in heart attacks so I painted this one which was suggested by a man shot in the eye with an arrow, depicted by Mantegna.

A beneficiary of the American GI bill, R B Kitaj arrived in Britain in 1958 to study at the Ruskin School of Drawing and Fine Art in Oxford. He "stayed on, and it became a habit."

Since then Kitaj has become one of the best known artists of his generation, which includes David Hockney, Howard Hodgkin, and Allen Jones. He is the first American since Sargent to be elected to both the Institute of Arts and Letters in New York and the Royal Academy, London. Robert Hughes, art critic of Time magazine, said, "Kitaj draws better than almost anyone else alive." Next year a large exhibition of his work opens at the Tate Gallery, London, where "Heart Attack" will be first exhibited.

Many of Kitaj's early pictures explored political or historical subjects-for example, "The Murder of Rosa Luxemburg" and "The Perils of Revisionism." Although the paintings usually deal very specifically with the past 100 years, allusions to paintings of earlier centuries are common. For example, the subject matter of "If Not, Not" is the murder of the European Jews by the Nazis (the Auschwitz gatehouse dominates the painting); yet "the general look of the picture was inspired by my first look at Giorgione's 'Tempesta'." Self portraits of Kitaj feature in several of his paintings, although they are usually jostling for attention with other figures, and the Kitaj figure is usually playing some complicated role.

Over the past decade his work has become increasingly autobiographical, with Kitaj's exploration of his Jewish identity providing the link between the political and the personal arenas. He quotes Cézanne's famous ambition, "To do Poussin over again, after Nature," and says he would like "To do Cézanne and Degas and Kafka over again, after Auschwitz."

"Heart Attack" and two other paintings dating from 1990 (which record his first sexual encounters 40 years earlier) are striking in that they address Kitaj's own experiences directly.' Despite being suggested

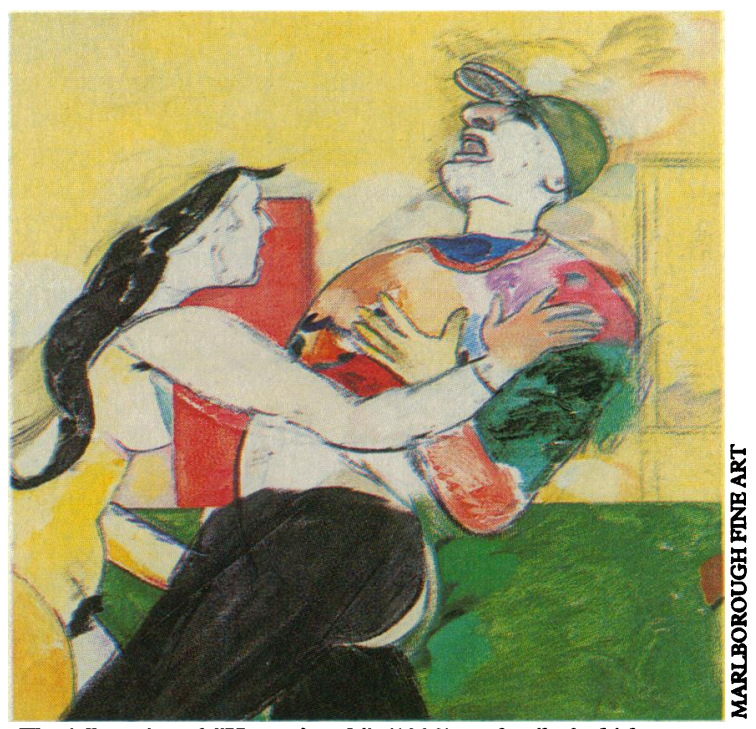

The full version of "Heart Attack" (1990), a detail of which appears on the cover

by an image of martyrdom "Heart Attack" is not about some imagined moment of death (and the nude woman is not the angel of death). Nevertheless, since his heart attack Kitaj says that he thinks about death every day, which he hardly ever did before.

After the heart attack, Kitaj's doctor advised him to take regular exercise. His early morning walks around South Kensington and Chelsea have provided him with a new range of subjects. ${ }^{1} \mathrm{He}$ may even get round to painting his heart hospital (the Brompton).-TONY DELAMOTHE, BM9

1 Livingstone M. Kitaj. London: Phaidon, 1992.

An exhibition of Kitaj's work opens at the Tate Gallery, London, on 15 June 1994. It transfers to the Los Angeles County Museum of Art in October and to the Metropolitan Museum, New York, in February 1995.

I thank R B Kitaj and Geoffrey Parton of Marlborough Fine Art for their help with this article. 